University of Wisconsin Milwaukee UWM Digital Commons

Theses and Dissertations

December 2014

\title{
Teaching Discriminated Social Approaches to Individuals with Angelman Syndrome
}

Caitlin Shea Fichtner

University of Wisconsin-Milwaukee

Follow this and additional works at: https://dc.uwm.edu/etd

Part of the Psychology Commons

\section{Recommended Citation}

Fichtner, Caitlin Shea, "Teaching Discriminated Social Approaches to Individuals with Angelman Syndrome" (2014). Theses and Dissertations. 688.

https://dc.uwm.edu/etd/688

This Dissertation is brought to you for free and open access by UWM Digital Commons. It has been accepted for inclusion in Theses and Dissertations by an authorized administrator of UWM Digital Commons. For more information, please contact open-access@uwm.edu. 
Caitlin S. Fichtner

\author{
A Dissertation Submitted in \\ Partial Fulfillment of the \\ Requirements for the Degree of \\ Doctor of Philosophy \\ in Psychology
}

at

The University of Wisconsin-Milwaukee

December 2014 


\title{
ABSTRACT \\ TEACHING DISCRIMINATED SOCIAL APPROACHES TO INDIVIDUALS WITH ANGELMAN SYNDROME
}

by

\author{
Caitlin S. Fichtner
}

The University of Wisconsin-Milwaukee, 2014 Under the Supervision of Professor Jeffrey H. Tiger

Angelman syndrome is a neuro-genetic disorder characterized by intellectual and developmental disability. Common behavioral characteristics of this disorder include a heightened interest in social interactions and frequent bids to initiate interaction. These bids can be problematic, for instance when a child attempts to hug strangers in public places. The purpose of the current study was to evaluate a discrimination training program to teach appropriate from inappropriate times to initiate a social interaction with three males diagnosed with Angelman Syndrome whose caregivers reported frequent hugging or hand holding as a problem. During a baseline, we alternated periods in which attention was delivered on an FR-1 schedule following social initiations with periods in which social initiations in the form of hugs or grabs were blocked (i.e., placed on extinction). Following this baseline, we implemented a discrimination training program to bring social initiations under the stimulus control of a salient discriminative stimulus and then presented that stimulus during FR-1 conditions in sessions that were similar to baseline. We evaluated the effects of presenting the discriminative stimulus in a combination reversal design and multiple baselines design across therapists. In the second baseline, the child's caregiver conducted sessions. Upon development of discriminated 
social initiations, we then extended treatment to the participants' homes during longer observation periods. 


\section{TABLE OF CONTENTS}

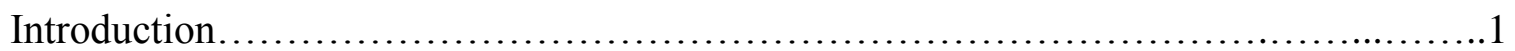

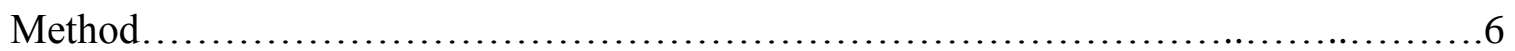

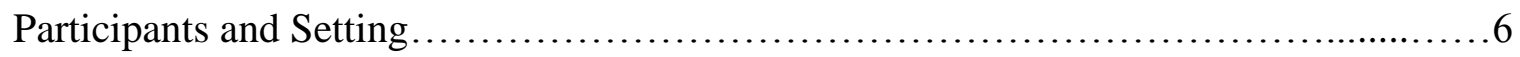

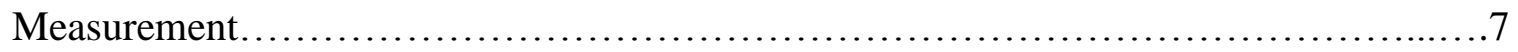

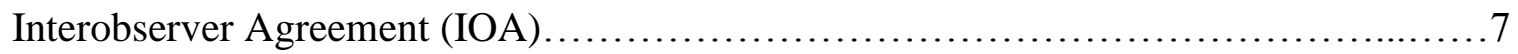

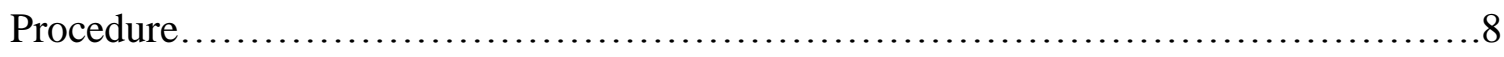

Baseline (Mixed Schedule)...................................................... 8

Multiple-Schedule-Discrimination Training ...................................... 10

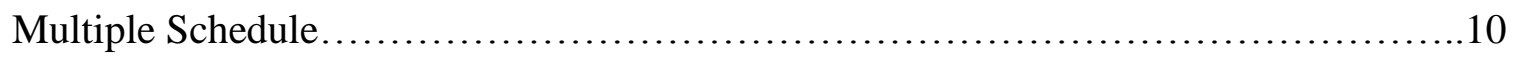

Treatment Extensions...............................................................

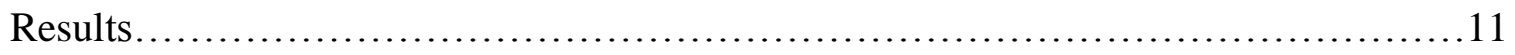

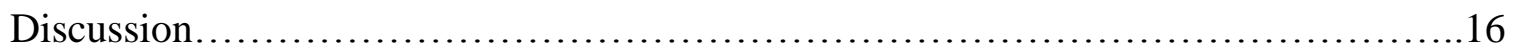

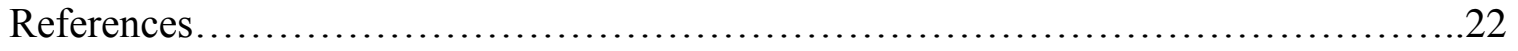

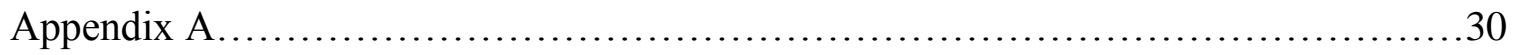

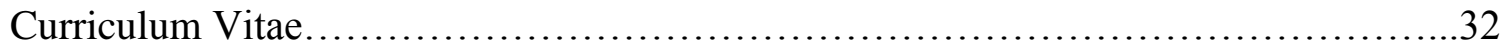




\section{LIST OF FIGURES}

Figure 1. Open circles represent social initiations made during extinction components and closed circles represent social initiations made during CRF components. Under mixedschedule conditions Marcus did not discriminate between CRF and EXT components but following multiple-schedule-discrimination training (not depicted) and the implementation of a multiple schedule a clear pattern of differentiated responding emerged with both the therapist and caregiver acting as therapist

Figure 2. Open circles represent social initiations made during extinction components and closed circles represent social initiations made during CRF components. Under mixedschedule conditions Justin did not discriminate between CRF and EXT components but following multiple-schedule-discrimination training (not depicted) and the implementation of a multiple schedule a clear pattern of differentiated responding emerged with both the therapist and caregiver acting as therapist. Note that although Justin engaged in low rates of social approaches with the caregiver as therapist, his responses were almost perfectly restricted to CRF components.....

Figure 3. Open circles represent social initiations made during extinction components and closed circles represent social initiations made during CRF components. Under mixed schedule conditions Allan did not discriminate between CRF and EXT components but following multiple-schedule-discrimination training (not depicted) and the implementation of a multiple schedule a there was immediate and pronounced separation

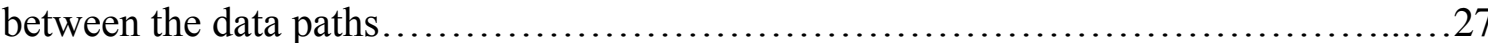

Figure 4. These data represent the percentage of social approaches made by each participant under CRF components during Mixed BL with the therapist (top panel) and caregiver as therapist (bottom panel) and post multiple-schedule-discrimination training. Note that each participant responded at indiscriminate levels during CRF components with the therapist and caregiver before discrimination training. However, following multiple-schedule-discrimination training each participant engaged in near perfect responding during the CRF component with both the therapist and caregiver. 


\section{LIST OF TABLES}

Table 1. Intervention Rating Profile (IRP-15) Caregiver Responses...................29 
Teaching Discriminated Social Approaches to Individuals with Angelman Syndrome Angelman syndrome (AS) is a genetic disorder that affects approximately 1/15,000 live births (Williams, 2008) and is caused by a missing or defective gene located on chromosome 15, specifically the UBE3A gene (Clayton-Smith, 2001). The majority of patients have a deletion of chromosome 15q11-13, though some have a defect in the imprinting process involving the $15 q 11-13$ region or a mutation of the UBE3A gene at this location. There appear to be clinical differences between these genetic types in mobility, speech ability and likelihood of developing seizures (Clayton-Smith, 2001). This disorder often goes undetected until approximately 6 to 12 months of age when parents notice developmental delays. Some characteristic symptoms of this syndrome include severe intellectual disability, minimal or no speech, ataxia, and dysmorphic facial features (e.g. deep-set eyes, a flat back of the head, a wide mouth which is often agape, and a prominent chin). Often, these individuals are prone to seizures and microcephaly (Clayton-Smith, 2010; Horsler \& Oliver, 2006). Individuals with AS also present with characteristic behaviors including a happy and excitable personality, frequent smiling, and outbursts of laughter (Clayton-Smith, 2001).

Individuals with AS are also characterized by a heightened interest in social interactions often involving displays of affection; in many cases this can be considered a behavioral strength of the disorder in that seeking additional social interactions provides a context for greater social learning opportunities. However, in many cases these social interactions can also be considered a problematic and potentially dangerous behavioral excess. Approaching and attempting to hug or kiss a stranger at the supermarket is clearly undesirable. Similarly, repeatedly approaching a familiar adult may also be problematic (e.g., hugging one's mother repeatedly in a short period of time; Mount, 
Oliver, Berg, \& Horsler, 2011). Such behaviors may represent a problem of frequency rather than topography. That is, it is clearly desirable for individuals to engage in affectionate behavior, but at more appropriate times or situations than they currently present. One way to conceptualize these issues is not that social initiations are a problem behavior that should be eliminated, but rather the occurrence of the behavior is under poor social stimulus control. Mount et al. (2011) conducted a study in which individuals with Angelman syndrome were observed during interactions with their mothers and an unfamiliar adult in which eye contact and interaction were systematically manipulated. Participants engaged in more social approaches towards their mothers than to strangers, but only when their mother was looking at them. These data suggest that although highrate social approaches are common among individuals with AS, it does appear that these approaches can be somewhat discriminated (e.g., by occurring more often with some people or with certain social cues).

One intervention approach may be to better bring these responses under the stimulus control of these natural cues (e.g., it is appropriate to hug one's mother, but it is not appropriate to hug novel individuals; it is appropriate to hug one's mother when she comes home from an outing, but not again until she leaves and returns). However, these social discriminations are likely more challenging than they appear. For instance, it would be appropriate to hug a caregiver who appeared upset, even if you just greeted them. Similarly, it is appropriate to hug a family member who you do not recognize (and in many situations it is a bigger social problem if you do not). Although teaching such social discriminations to natural social stimuli should be a long-term goal, it may be desirable to bring social bids under control of contrived stimuli that can be presented and 
withdrawn by a caregiver as a more immediate solution. That is, arranging a single, salient go/no-go cue that can be presented by a parent may be more effective as a short term solution; stimulus control could then be transferred to more natural stimuli. These procedures are commonly referred to as arranging a multiple schedule of reinforcement. Multiple schedules of reinforcement are ones in which two simple schedules of reinforcement alternate (typically based upon the passage of time) and each schedule is associated with a unique discriminative stimulus. In the case of social approaches, periods in which social approaches would result in reinforcement (perhaps on a continuous reinforcement schedule) would alternate with periods in which social approaches would result in extinction and a salient cue would be provided during each period. Multiple schedules can be contrasted with mixed schedules. Mixed schedules involve two or more reinforcement schedules that alternate over time, but a unique discriminative stimulus is not correlated with each schedule (the natural environment may be considered an analog to a mixed schedule in which individuals with AS are not attending to relevant social discriminative stimuli to predict the availability of reinforcement). Thus, intervention would involve arranging more salient discriminative stimuli that indicate when reinforcement and extinction contingencies are in place. After several pairings of the discriminative stimuli with the active contingencies, responding comes under the control of these stimuli.

The applied use of multiple schedules of reinforcement has been described recently in the context of treating severe problem behavior (e.g. Fisher, Kuhn, \& Thompson, 1998; Hanley, Iwata, \& Thompson, 2001; Neidert, Iwata, \& Dozier, 2005) or in ill-timed or excessive requests (e.g., Grow, LeBlanc, \& Carr, 2010; Sidener, Shabani, 
Carr, \& Roland, 2006; Tiger \& Hanley, 2004; 2005; Tiger, Hanley, \& Heal, 2006).

These studies typically progress by teaching a novel communicative response and then bringing that response under stimulus control within a multiple schedule. For instance, Fisher, Kuhn, and Thompson (1998) taught two participants to request access to attention (the functional reinforcer maintaining problem behavior in these cases) and to a toy (an alternative reinforcer). Only one of these reinforcers was arranged to be available at any time; the experimenters presented either colored drawings of or pictures of toys as discriminative stimuli to signal these times.

One recent study evaluated the use of these multiple schedules in developing stimulus control over the social approaches of four individuals with AS (Heald et al., 2013). This study utilized a trial-based format. If the participants initiated a social approach during a reinforcement trial, then they received $10 \mathrm{~s}$ of social interaction. If the participants engaged in a social approach during an extinction trial, then no social interaction followed and the trial was terminated. The experimenters arranged a multiple schedule by having the therapist wear a brightly colored jacket during reinforcement trials. Training began by initially presenting a greater density of reinforcement trials relative to extinction trials (5:2) and then gradually equating the number of exposures of each (3:3). Due to the participants' slow progress and failure to reach mastery, the experimenters advanced participants through this progression every 5 sessions rather than based upon a demonstrated discrimination. In total, each participant experienced 25 to 35 training sessions, but this procedure failed to produce discriminated responding characterized by reductions in extinction-trial responding. 
There are a number of potential reasons the Heald et al. (2013) procedure failed to produce discriminated responding. One explanation may be that the 25 to 35 sessions of exposure to the contingencies were not sufficient to promote discriminated responding and that additional training trials would have resulted in discriminated responding. This is possible, but the social validity of such procedures needs to be considered. That is, the efficiency of training procedures will be important to consumers and training much beyond the number of trials described by Heald et al. seems unreasonable. Thus a more profitable approach would be to enhance the likelihood of discriminated responding developing.

In Tiger and Hanley (2004), the social approaches of three preschool-aged children of typical development were arranged into a multiple schedule in which reinforcement periods were signaled by the teacher wearing a red floral lei and extinction periods were signaled by the teacher wearing a blue floral lei. Children did not engage in discriminated responding following over 12 sessions of exposure to these contingencies until the experimenters included presession descriptive rules (e.g., when I am wearing the red lei, I can talk to you and answer your questions) and presession prompting to contact the contingencies associated with each stimulus (e.g., when I put on the red lei, say, "Hi"). Such instructions and prompting (a) required participants to engage in an attending response to the programmed stimuli, (b) ensured a response occurred while the participant attended to the stimulus, and (c) ensured repeated contact with the programmed contingencies. Perhaps prompting an attending response to the programmed stimuli and immediately prompting a target response may help promote discriminated responding in individuals with Angelman syndrome as well. 
Assuming this modification is sufficient to bring social bids of individuals with AS under stimulus control, there are also important questions of generality that need to be considered. That is, the training described by Heald et al. (2013) involved the use of contrived discriminative stimuli presented by a trained experimenter. For these procedures to have practical utility, these stimuli will also need to control social bids in the presence of more relevant people (e.g., caregivers) in more natural situations (e.g., at home or in the community).

The current study extended the work by Heald et al. (2013) examining multiple schedules of reinforcement to teach discriminated social approaches to individuals with AS using salient, contrived discriminative stimuli. Unlike Heald et al., the current discrimination training procedures included response prompting to facilitate the development of discriminated responding. Furthermore we examined the generality of the multiple-schedule stimuli in promoting discriminated social approaches with participants' caregivers and in the natural environment.

\section{Method}

\section{Participants and Setting}

Three individuals with AS participated in the current study; each were recruited through paper and email solicitations to pediatricians, case workers, and the Angelman Syndrome Foundation, Inc. The first three individuals who responded who (a) had a medical diagnosis of Angelman's syndrome made by a licensed physician, (b) were aged 10 years or older, (c) were self-ambulatory, (d) had a reported difficulty in making illtimed or ill-directed social approaches, (e) engaged in social approaches in the presence of an experimenter during baseline observations, and (f) had a caregiver available to 
participate with them were included. These caregivers also nominated the topographies of social initiations they considered problematic for their children. Marcus was a 17 yearold male; he participated with this mother who identified frequent hugging as problematic. Justin was a 16 year-old male; he participated with his grandmother who also identified frequent hugging as problematic. Allan was a 12 year-old male; he participated with this mother who identified frequent grabbing as problematic. Marcus and Justin's initial evaluations were conducted in experimental rooms on the campus of a Midwestern university with follow up and generalization sessions collected in the participants' homes. Allan's evaluation was completed entirely in the living room of his family's home.

\section{Measurement}

Observers collected data on the frequency of the participants' social initiations and the therapist's response using pencil-and-paper data sheets in which each session was divided into 10-s intervals and target behaviors were scored by making tally marks in appropriate intervals. For Marcus and Justin, we defined social initiations as (a) placing one or both hands or arms around the torso or shoulder of a therapist past their side or (b) contact of his head or face against the torso of a therapist. For Allan, we defined social initiations as closure of the hand around the therapist's hand, wrist, or arm. The therapist's response was scored as reciprocation if the therapist returned the hug (Marcus and Justin) or allowed Allan to hold her arm or hand.

\section{Interobserver Agreement (IOA)}

A second observer simultaneously, but independently, collected data during $39 \%$ of Marcus' sessions, 51\% of Justin's sessions, and 64\% of Allan's sessions. We 
compared observers' records on an interval-by-interval basis to assess interobserver agreement (IOA). Intervals in exact agreement were given a score of 1 ; intervals not in exact agreement were given a proportional agreement score by dividing the smaller number of scored responses by the larger number of scored responses. The agreement scores were then summed across intervals, divided by the total number of intervals, and converted into a percentage. Observers mean IOA was $97 \%$ (range, $80 \%$ to 100\%), $99 \%$ (range, $93 \%$ to $100 \%$ ), and $96.4 \%$ (range, $72 \%$ to $100 \%$ ) for social approaches for Marcus, Justin, and Allan, respectively and 96\% (range, 78\% to 100\%), 99\% (range, 93\% to $100 \%$ ), and $97.3 \%$ (range, $85 \%$ to $100 \%$ ) for therapist reciprocation to Marcus, Justin, and Allan, respectively.

\section{Procedure}

We evaluated the effects of the multiple schedule when implemented by a trained therapist (primary author) and by a caregiver. Caregivers conducted probe sessions under mixed schedule conditions until the participants had demonstrated discriminated responding under the multiple schedule with the trained therapist. The primary author then trained caregivers to implement procedures using modeling and live coaching during sessions in order to maintain high levels of procedural fidelity. The initial effects of multiple schedule training were evaluated in a reversal design with each participant and then a multiple-baseline design across implementers.

Baseline (Mixed Schedule). Each baseline session, whether implemented by the therapist or the caregiver, was 5 min in duration and consisted of alternating periods in which social initiations were reinforced on a continuous reinforcement schedule (CRF components) and periods in which social initiations did not result in reinforcement 
(extinction or EXT components). The presumed reinforcer for social initiations in these cases was the reciprocation of that initiation. For instance, in Marcus' and Justin's cases, where social initiations took the form of hugging, during CRF components the therapist reciprocated each hug for approximately 3 to $5 \mathrm{~s}$ and during EXT components the therapist blocked all attempts to hug by guiding the participants' hands down to his sides. Allan's social initiations took the form of grabbing or hand holding and all attempts to hold or grab the therapist's hands during CRF components were permitted but were disrupted during EXT components. CRF and EXT components each occurred three times per session for durations of $30 \mathrm{~s}, 50 \mathrm{~s}$, and $70 \mathrm{~s}$ (i.e., a total of six components per session). We kept the duration of these components brief and irregular to minimize the likelihood of discrimination between components based solely on the passage of time (as was seen in Tiger \& Hanley, 2005).

During baseline, there were no programmed discriminative stimuli to indicate which component was in effect (i.e., a mixed schedule of reinforcement was in place). That is, the therapist escorted the participant into the experimental space and prompted the participant to engage with a variety of available leisure items. This procedure was modified for Justin, who received access to age appropriate toys as well as age appropriate conversational statements on a Fixed-Time $30 \mathrm{~s}$ schedule. When the therapist was not delivering attention, her gaze was averted from the subject regardless of the component. We continued this phase for a minimum of three sessions and until levels of responding during $\mathrm{CRF}$ and $\mathrm{EXT}$ components were undifferentiated (i.e., indicating no discrimination between conditions) based upon visual inspection. 
Multiple-Schedule-Discrimination Training. The purpose of this phase was to teach participants to discriminate between periods in which their social approaches would and would not be reciprocated. In each case, we identified signals to present as discriminative stimuli for each component in consultation with the participant's caregivers; all caregivers chose a laminated "smiley face" on a lanyard necklace to serve as an $\mathrm{S}+$. Each training session included 10 trials. At the onset of each trial, the therapist said the participant's name, waited for the participant to make eye contact, presented the S+ by placing the necklace around her neck, and immediately prompted a social initiation using a three-step (vocal, model, and physical) graduated-prompting procedure. All social initiations, regardless of prompt level, while the $\mathrm{S}+$ was in place resulted in 3 to $5 \mathrm{~s}$ of therapist reciprocation. After reinforcement delivery, the experimenter withdrew the $\mathrm{S}+$ and waited 3 to $5 \mathrm{~s}$ prior to initiating the next trial. This 3 to $5 \mathrm{~s}$ inter-trial interval (ITI) functionally served as brief S- trials as any attempts at social initiation would have been blocked. Once participants initiated social approaches following the vocal prompt on $90 \%$ or more of trials, we then delayed the presentation of the vocal prompt to $10 \mathrm{~s}$ following the presentation of the $\mathrm{S}+$ to promote independent responding. Once social approaches occurred on $90 \%$ of trials prior to the vocal prompt, we then terminated the training procedure and moved onto the multiple-schedule evaluation.

Multiple Schedule. Sessions during the multiple schedule were identical to baseline (Mixed Schedule) except the therapist presented the S+ continuously during CRF components and removed the $\mathrm{S}+$ during EXT components (i.e., $\mathrm{S}+$ removal was programmed as an S- for responding). Additionally, the prompting procedure used during discrimination training was kept in effect. That is, 10-s following the presentation 
of the $\mathrm{S}+$, the therapist would present a vocal prompt for a social initiation if none had occurred (note, prompted responses are not reflected in the presented data). These prompts continued to be faded in 10-s intervals following two consecutive sessions in which the participant responded independently at stable or increasing levels. After reaching a 30-s prompt delay prompting was eliminated entirely. Prompts were terminated at session 32 for Marcus, session 24 for Justin, and session 19 for Allan. Note that the fading procedure was only in place during the first exposure with the therapist; no prompting was provided during the subsequent reversal nor when implemented by the participants' caregivers.

Treatment Extensions (Marcus and Justin only). After observing discriminated social approaches under multiple-schedule conditions with the therapist and caregiver, we then evaluated the multiple-schedule arrangement in more normative conditions, depending upon caregiver availability. We conducted sessions in participants' homes; these sessions were otherwise conducted identically to those by their caregivers in the experimental room. We also extended session duration from $5 \mathrm{~min}$ to $15 \mathrm{~min}$ and extended the duration of individual components to provide a better analog to the conditions the participants would experience in the home after treatment was completed.

\section{Results}

Marcus's data are shown in Figure 1 with sessions conducted by the therapist in the top panel and sessions conducted by his caregiver in the bottom panel. During the mixed-schedule baseline (Mixed BL) with the therapist, Marcus initiated social interactions at similar rates during both $\operatorname{CRF}(M=.2$ per min $)$ and EXT components $(M=$ .1 per min); these data indicate that in the absence of programmed cues, Marcus did not 
discriminate components in which social initiations would be reinforced. We then conducted multiple-schedule-discrimination training; Marcus required 18, 10-trial sessions to meet mastery criteria (data not shown on Figure 1). The multiple schedule was then evaluated. Social initiations during CRF components increased $(M=1.3$ per min) and remained elevated well above social initiations during extinction components $(M=.1$ per min). We conducted a reversal to the mixed-schedule condition by removing the $\mathrm{S}+$ presentations and social initiations again occurred at lower, but equal levels across $\operatorname{CRF}(M=.3$ per $\min )$ and $\operatorname{EXT}(M=.1$ per min $)$ components. We then re-implemented the multiple schedule and saw a return of discriminated approaches with high levels during $\operatorname{CRF}(M=1.1$ per min) and low levels during $\operatorname{EXT}(M=.1$ per min). It is worth noting that although discriminated approaches were observed during the initial multiple schedule condition, this occurred primarily as a result of accelerated responding during the CRF condition. The level of extinction responding did not reduce relative to the initial baseline. However, in the second and prolonged exposure to the multiple-schedule condition, EXT-component responding was virtually eliminated.

Concurrent with Marcus's sessions with the therapist, his caregiver also conducted sessions initially under Mixed BL conditions. Similar to the sessions with the therapist, social approaches occurred at indiscriminate rates across CRF $(M=.1$ per min) and $\operatorname{EXT}(M=.2$ per min). She then began to implement the multiple schedule and we saw immediate discriminated approaches between CRF $(M=1.4)$ and EXT components $(M=.1)$. We then evaluated the multiple-schedule arrangement in the family's home and extended session durations to $15 \mathrm{~min}$. Social approaches remained elevated during CRF 
components $(M=.9)$ and no approaches occurred during EXT components in the family's home (i.e., discrimination was perfect in the natural environment).

Justin's data are displayed in Figure 2 with sessions conducted by the therapist in the top panel and sessions conducted by his caregiver in the bottom panel. During the mixed-schedule baseline (Mixed BL) with the therapist, Justin initiated social interactions at comparable rates during both $\operatorname{CRF}(M=.4$ per min $)$ and $\operatorname{EXT}(M=.3$ per min $)$ components. These data show that in the absence of programmed discriminative stimuli, Justin did not discriminate appropriate and inappropriate times to initiate social interactions. We then conducted multiple-schedule-discrimination training; Justin completed 22, 10-trial sessions to meet mastery criteria (data not shown); we then evaluated the multiple-schedule arrangement. During CRF components, social initiations increased $(M=2.3$ per $\min )$ and remained elevated relative to social initiations during extinction components $(M=.2$ per $\min )$. We conducted a brief reversal to the mixedschedule condition by removing discriminative stimulus presentations and social initiations returned to lower, indiscriminate levels across $\mathrm{CRF}(M=.3$ per min) and EXT $(M=.1$ per $\min )$ components. We re-implemented the multiple schedule and saw a return of discriminated social approaches with higher levels during the CRF component $(M=.9$ per $\min )$ and low levels during $\operatorname{EXT}(M=.1$ per min). Similar to Marcus' data, initial discriminated responding was a result of accelerated CRF component responding, but after repeated exposure EXT responding decreased to zero levels.

Concomitant with Justin's therapist-conducted sessions, his caregiver also conducted sessions initially under Mixed BL conditions. Similar to the sessions with the therapist, social approaches occurred at indiscriminate rates across CRF $(M=.3$ 
responses per min) and EXT $(M=.4$ per min). Justin's caregiver then began to implement the multiple schedule and we saw an immediate discrimination between CRF $(M=.2$ per $\min )$ and $\operatorname{EXT}(M=<.1$ per $\min )$ components although responding remained at low rates. We then assessed the multiple-schedule arrangement in the family's home and extended session durations to $15 \mathrm{~min}$. Social approaches remained elevated during CRF components $(M=.3)$ and no approaches occurred during EXT components $(M=.0)$ in the family's home.

Allan's data are illustrated in Figure 3 with sessions conducted by the therapist in the top panel and sessions conducted by his caregiver in the bottom panel. Under Mixed BL conditions with the therapist, Allan initiated social interactions at similar rates during both the $\operatorname{CRF}(M=1.5$ per min) and EXT components $(M=1.3$ per min). Allan required 11, 10-trial sessions to meet mastery criteria in the multiple-schedule discrimination training. Social initiations increased during CRF components $(M=1.5$ per $\min )$ of the multiple schedule and were elevated relative to social approaches made during extinction components $(M=.1$ per $\min )$. We conducted a reversal to the mixed-schedule condition by removing $\mathrm{S}+$ presentations and social initiations again occurred at comparable levels during the $\operatorname{CRF}(M=1.6$ per $\min )$ and $\operatorname{EXT}(M=.9$ per min $)$ components. We reimplemented the multiple schedule and saw a return of discriminated social approaches with high levels during CRF $(M=2.8$ per min) and lower levels during $\operatorname{EXT}(M=.1$ per $\min )$.

Concurrent with Allan's sessions with the therapist, his caregiver also conducted sessions initially under Mixed BL conditions. Similar to therapist-run sessions, social approaches occurred at indiscriminate rates across $\operatorname{CRF}(M=.7$ per min $)$ and $\operatorname{EXT}(M=$ 
.5 per min) components. The caregiver then began to implement the multiple schedule and we saw immediate discrimination between CRF $(M=2.1$ per min $)$ and EXT components $(M=.2$ per $\min )$. We did not conduct any additional treatment extension sessions because all of Allan's sessions were conducted in his home from the onset of the evaluation.

As a summary measure, we calculated discrimination indices for each participant under Mixed and Multiple schedule conditions implemented by both the therapist and the caregivers; these data are presented in Figure 4. Discrimination indices were calculated by dividing the total number of responses occurring during CRF components by the total number of responses in CRF and EXT components and converting this fraction into a percentage. Thus, a percentage of $50 \%$ would be indicative of indiscriminate responding (i.e., half of all responses occurred during CRF components) and a percentage of $100 \%$ would be indicative of perfectly discriminated responding (i.e., all responses occurred during CRF components). During mixed-schedule conditions conducted by the therapist, $64 \%$ of Marcus' social approaches were made during CRF components compared to $94 \%$ during multiple-schedule conditions, highlighting the improved discrimination. Similar results were seen with Justin (65\% increased to 94\%) and with Allan (55\% increased to 95\%). Each participant's discrimination also improved when the multiple schedules were implemented by their caregivers $(30 \%$ to $94 \%, 44 \%$ to $91 \%$, and $59 \%$ to $90 \%$ for Marcus, Justin, and Allan, respectively).

Following treatment, Justin and Allan's caregivers completed satisfaction surveys (a modified version of the Intervention Rating Profile-15; Martens, Witt, Elliott, \& Darveaux, 1985) to ascertain the social validity of the intervention; their responses are 
summarized in Table 1. Both caregivers responded favorably to the ease and effectiveness of the discrimination training and multiple-schedule intervention utilized for this study $(M=5.4)$.

\section{Discussion}

The current study arranged the availability of social reinforcement for problematic social initiations in a multiple schedule of reinforcement with three individuals with AS. Periods in which reinforcement was available were signaled by the presentation of a single, salient $\mathrm{S}+$ stimulus and periods in which reinforcement was not available were signaled by the removal of the $\mathrm{S}+$ stimulus. We found that each of our participants engaged in discriminated social approaches following multiple-schedule-discrimination training. These results differ considerably from Heald et al. (2013) who also examined multiple-schedule arrangements for individuals with AS, but failed to develop discriminated social approaches. Heald et al. raised some concerns whether individuals with AS were capable of making such social discriminations; the current data show that indeed they are capable.

We made a number of procedural modifications to the training procedures described by Heald et al. (2013) that may have contributed to the success of our procedures. Among those modifications, we prompted the occurrence of social approaches following each presentation of the $\mathrm{S}+$ to promote the development of stimulus control over the occurrence of social approaches and gradually faded out those prompts. By contrast, Heald et al. did not include any prompting. Instead they relied on unprompted social approaches contacting programmed reinforcement and extinction contingencies in presence or absence of their relevant $\mathrm{S}+$. This may be an effective 
procedure when responding is occurring at a high rate and thus makes more frequent contact with programmed reinforcement and extinction contingencies. However, based upon the baseline rates of responding in the current study, we felt that stimulus control was unlikely to develop based solely upon contingency control. Additionally, when relying exclusively on behavioral contact with contingencies, it is possible that participants will not attend to the programmed discriminative stimulus prior to engaging in an approach response. Our prompting procedure specifically required an attending response just prior to the social approach to ensure an association between the two stimuli (and that the response occurred with a minimal latency following the $\mathrm{S}+$ ).

Second, we included a separate multiple-schedule-discrimination training procedure which allowed us to increase participant exposure to programmed reinforcement and extinction contingencies to facilitate stimulus control over social approach behavior. In the procedures described by Heald et al. (2013) participants were exposed to 25 to 35 total discrimination training sessions, each session consisted of either 6 or 7 teaching trials. Sessions included 4 potential ratios of reinforcement-to-extinction trials. The ratios were 5:2, 4:2, 4:3, and 3:3 reinforcement-to-extinction, respectively. As participants reached a set discrimination criterion; extinction trials were to be systematically increased. However, due to slow progress and failure to reach the set mastery criterion, the experimenters decided that reinforcement-to-extinction ratios would be changed every 5 sessions regardless of participant performance. By contrast, the multiple-schedule-discrimination training procedure in the current study consisted of 10-trial sessions and included a specific mastery criteria be met before implementing the multiple schedule. Once participants initiated social approaches following a vocal 
prompt on $90 \%$ or more of trials, we then delayed the presentation of the vocal prompt to $10 \mathrm{~s}$ following presentation of the $\mathrm{S}+$. Once social approaches occurred on $90 \%$ of trials prior to the vocal prompt we then terminated the training procedure. This meant that before experiencing the multiple-schedule arrangement, each participant received an individualized number of training trials based upon his performance rather than advancing to the multiple schedule according to a universal advancement criteria based upon the passage of time.

We also extended prior research by evaluating multiple-schedule implementation by caregivers and in their natural environments. Although multiple-schedules have been described across a variety of populations, these procedures have been implemented near universally by trained researchers (see Cammilleri, Tiger, \& Hanley, 2008 for a notable exception with teachers). In each of the three current cases, a caregiver was trained to implement the multiple-schedule procedure and did so with sufficient integrity to produce discriminated responding. Further, each caregiver also implemented the multiple schedule in their home and in doing so demonstrated the generality of this intervention. That is, caregivers were able to promote discriminated social approaches in the natural environment.

Not only were caregivers capable of implementing this procedure in the natural environment, their responses to the social validity survey indicated they found the procedures and outcomes socially acceptable as well. Although caregiver report is a valuable indicator of consumer satisfaction, it is an indirect measure of the behavior of interest. That is, we are most concerned not with how acceptable caregivers found the procedures and outcomes, but rather did caregivers find them sufficiently acceptable to 
continue implementing these procedures following the conclusion of the study. Future research should collect such follow up data to determine the maintenance of caregivers' implementation of these procedures.

Along with questions of long-term implementation will also come questions of long-term procedural fidelity. During the course of the current study, we provided caregivers with immediate feedback to ensure high levels of procedural fidelity as our primary concerns were in regards to the clients' responsiveness to the programmed discriminative stimuli. However, outside of their participation, it seems likely that caregivers will make errors by intermittently not reinforcing approaches during CRF periods or by intermittently reinforcing approaches during EXT periods. It is not clear how detrimental each type of procedural integrity failure would be, but similar questions have been asked in the context of DRA interventions in which appropriate communication should be reinforced and problem behavior should be placed on extinction (St. Peter-Pipkin, Vollmer, \& Sloman, 2010). Such data suggests that reinforcement of problem behavior while extinction is particularly problematic, whereas errors of intermittent reinforcement of an appropriate behavior are less problematic. However, in DRA appropriate behavior and problem behavior are generally topographically distinct responses whereas multiple-schedule arrangements typically involve a single response under two stimulus conditions. Thus, errors of intermittent reinforcement may accelerate responding such that it carries over into extinction periods. Such integrity evaluations will be useful in subsequent research as will more formal caregiver training procedures. 
Given that the main referring problem for these participants was ill-timed social approaches, the clinical goal for these participants was to reduce EXT period responding to near zero levels. Interestingly though, the early stages of exposure to the multiple schedule produced discriminated responding without suppressing extinction responding. That is, in the initial multiple schedule phases, EXT responding remained at baseline levels while CRF responding increased dramatically. Only during continued exposure to the multiple schedule did EXT responding decrease to consistent near zero levels; this pattern was repeated across Marcus and Justin's data. We interpret these data as a gradual strengthening of the stimulus control exerted by the presence and absence of the lanyard in the current study and suggest that developing such inhibitory stimulus control may require extended exposure to this arrangement. It is also possible that this delayed reduction may be conceptualized as a satiation effect. That is, the acceleration in responding during CRF periods resulted in substantially higher densities of reinforcement than during baseline and as a result the value of approach reciprocation may then have been minimized increasing behavioral sensitivity to extinction contingencies.

It may be possible to facilitate suppression of EXT responding earlier by strengthening an incompatible response during those time periods. For instance, Fisher, Kuhn, and Thompson (1998) arranged a multiple schedule for the attention requests of two children treated for severe destructive behavior maintained by attention delivery. During S+ periods, attention was delivered for each request and during S- periods, in which attention was unavailable, the experimenters made an alternative reinforcer, preferred toys, available. In the current preparation, it may be possible to make lanyard 
removal discriminative both for attention unavailability and the availability of an alternative reinforcer delivered for engagement with leisure materials.

As noted previously, the use of an arbitrary stimulus as an $\mathrm{S}+$ should be a shortterm goal to facilitate complex social discriminations with a long-term goal of transferring that stimulus control to more normative social cues (e.g., Kuhn, Chirighin, \& Zelenka, 2010), but the procedures for teaching such typical discriminations are not well developed. The use of arbitrary signals is an effective and socially acceptable means of minimizing ill-timed approaches while applied researchers continue to refine discrimination training procedures. 


\section{References}

Clayton-Smith, J. (2001). Angelman syndrome: Evolution of the phenotype in adolescents and adults .Developmental Medicine \& Child Neurology, 43, 476480. doi: 10.1111/j.1469-8749.2001.tb00746.x

Clayton-Smith, J. (2010). Angelman syndrome. Journal of Pediatric Neurology, 8, 97-99. doi: 10.3233/JPN-2010-0372

Fisher, W. W., Kuhn, D. E., \& Thompson, R. H. (1998). Establishing discriminative control of responding using functional and alternative reinforcers during functional communication training. Journal of Applied Behavior Analysis, 31, 543-560. doi: 10.1901/jaba.1998.31-543

Grow, L. L., LeBlanc, L. A., \& Carr, J. E. (2010). Developing stimulus control of the high-rate social-approach responses of an adult with mental retardation: A multiple-schedule evalaution. Journal of Applied Behavior Analysis, 43, 285-289. doi: 1031901/jaba.2010.43-285

Hanley, G. P., Iwata, B. A., \& Thompson, R. H. (2001). Reinforcement schedule thinning following treatment with functional communication training. Journal of Applied Behavior Analysis, 34, 17-38. doi: 10.1901/jaba.2001.34-17

Heald, M., Allen, D., Villa, D., \& Oliver, C. (2013). Discrimination training reduces high rate social approach behaviors in Angelman syndrome: Proof of principle. Research in Developmental Disabilities, 34, 1794-1803. doi:

10.1016/j.ridd.2013.02.012 
Horsler, K., \& Oliver, C. (2006). The behavioural phenotype of Angelman syndrome. Journal of Intellectual Disability Research, 50, 33-53. doi: 10.1111/j.1365-2788-2005.00730.x

Kuhn, D. E., Chirighin, A. E., \& Zelenka, K. (2010). Discriminated functional communication: A procedural extension of functional communication training. Journal of Applied Behavior Analysis, 43, 249-264. doi: 10.1901/jaba.2010.43249

Martens, B. K., Witt, J. C., Elliot, S. N., \& Darveaux, D. X. Teacher judgments concerning the acceptability of school-based interventions.. Professional Psychology: Research and Practice, 16, 191-198. doi: $10.1177 / 073428298600400404$

Mount, R., Oliver, C., Berg, K., \& Horsler, K. (2011). Effects of adult familiarity on social behaviours in Angelman syndrome. Journal of Intellectual Disability Research, 55(3), 339-350. doi: 10.1111/j.1365-2788.2010.01364.x

Neidert, P. L., Iwata, B. A., \& Dozier, C. L. (2005). Treatment of multiply controlled problem behavior with procedural variations of differential reinforcement. Exceptionality, 13, 45-53. doi: 10.1207/s15327035ex1301_6

Sidener, T. M., Shabani, B. D., Carr, J. E., \& Roland, J. P. (2006). An evaluation of strategies to maintain manding at practical levels. Research in Developmental Disabilities, 27, 632-644. doi: 10.1016/j.ridd.2005.08.002

St. Peter-Pipkin, C. C., Vollmer, T. R., \& Sloman, K. N. (2010). Effects of treatment integrity failures during differential reinforcement of alternative behavior: A 
translational model. Journal of Applied Behavior Analysis, 43, 47-70. doi:

10.1901/jaba.2010.43-47

Tiger, J. H., \& Hanley, G. P. (2004). Developing stimulus control of preschooler mands: An analysis of schedule-correlated and contingency-specifying stimuli. Journal of Applied Behavior Analysis, 37, 517-521. doi: 10.1901/jaba.2004.37-517

Tiger, J. H., \& Hanley, G. P. (2005). An example of discovery research involving the transfer of stimulus control. Journal of Applied Behavior Analysis, 38, 499-509. doi: 10.1901/jaba.2005.139-04

Tiger, J. H., Hanley, G. P., \& Heal, N. A. (2006). The effectiveness of and preschoolers' preferences for variations of multiple-schedule arrangements. Journal of Applied Behavior Analysis, 39, 475-488. doi: 10.1901/jaba.2006.48-06

Williams, C. (2008, November 08). Incidence statistics. Retrieved from http://www.angelman.org/understanding-as/medical-info/incidence-statistics/ 


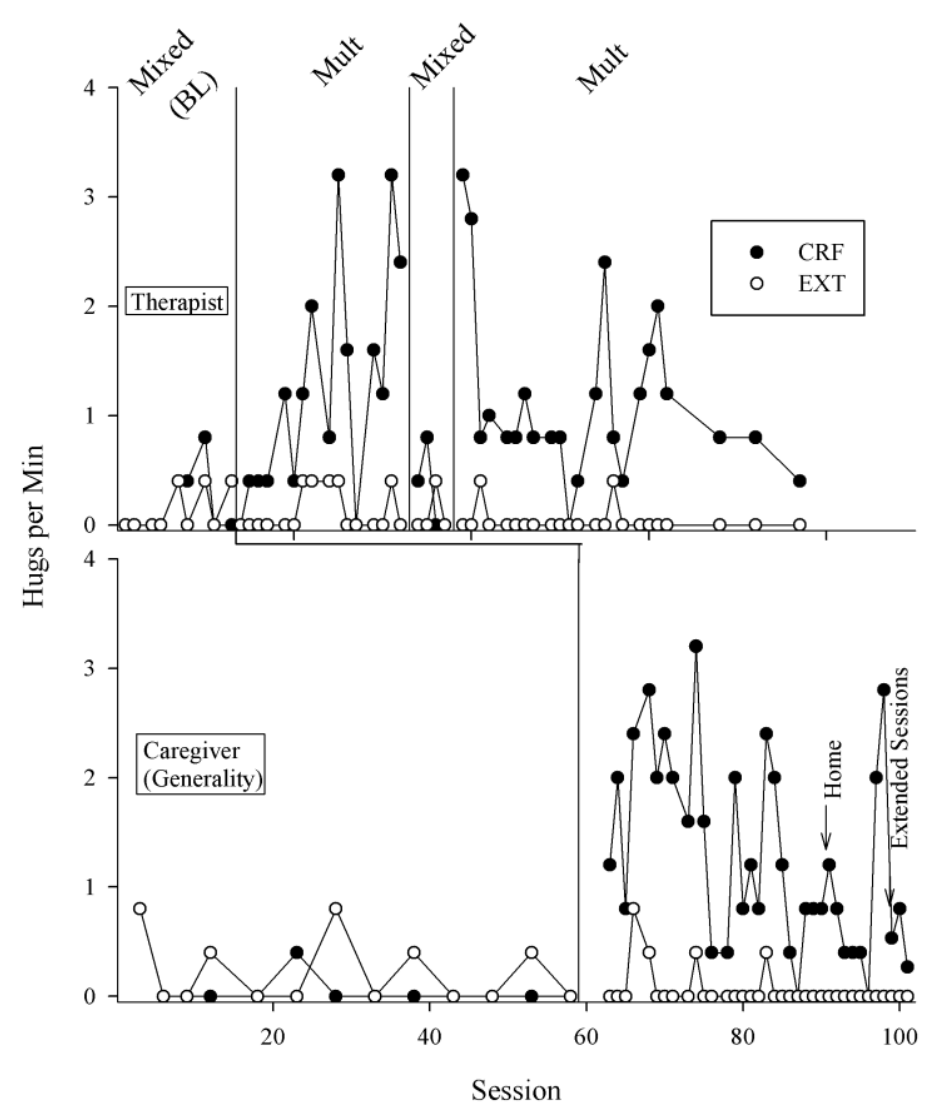

Figure 1. Open circles represent social initiations made during extinction components and closed circles represent social initiations made during CRF components. Under mixed-schedule conditions Marcus did not discriminate between CRF and EXT components but following multiple-schedule-discrimination training (not depicted) and the implementation of a multiple schedule a clear pattern of differentiated responding emerged with both the therapist and caregiver acting as therapist. 


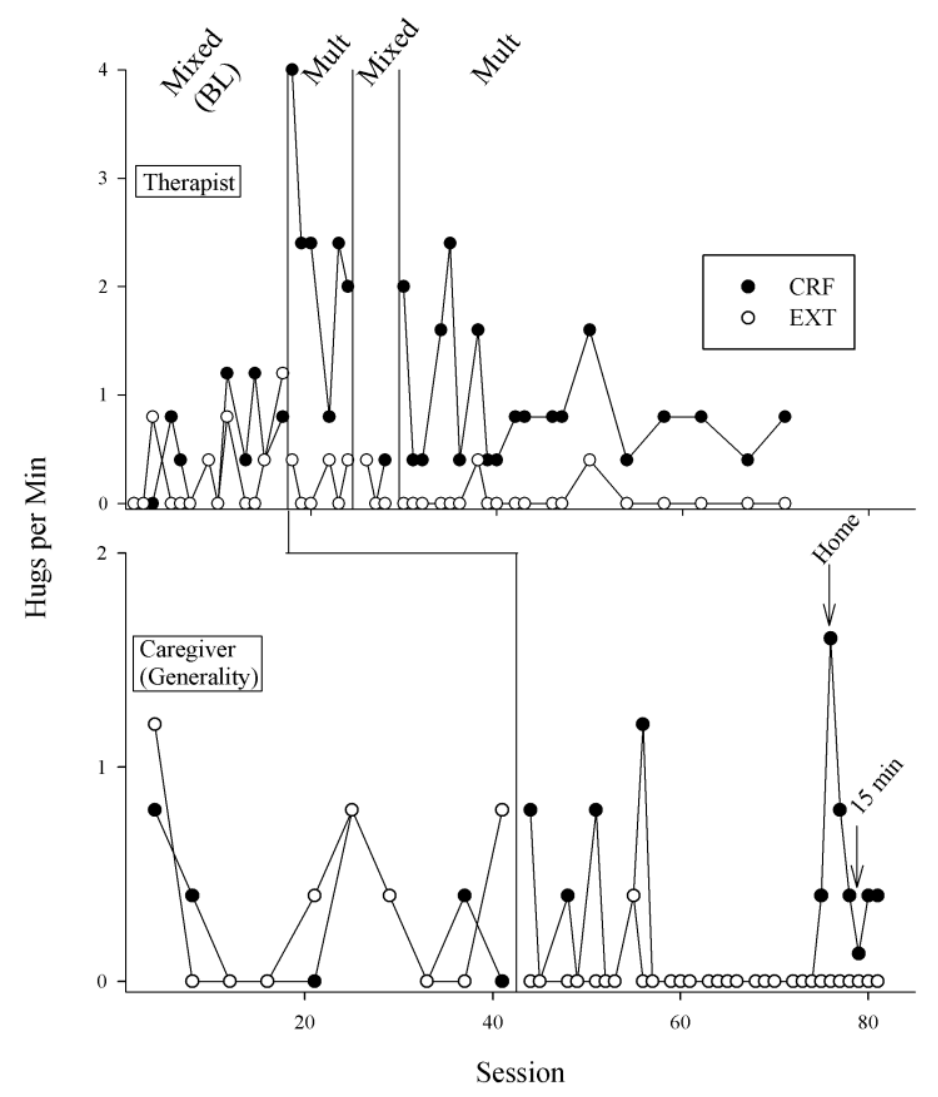

Figure 2. Open circles represent social initiations made during extinction components and closed circles represent social initiations made during CRF components. Under mixed-schedule conditions Justin did not discriminate between CRF and EXT components but following multiple-schedule-discrimination training (not depicted) and the implementation of a multiple schedule a clear pattern of differentiated responding emerged with both the therapist and caregiver acting as therapist. Note that although Justin engaged in low rates of social approaches with the caregiver as therapist, his responses were almost perfectly restricted to CRF components. 


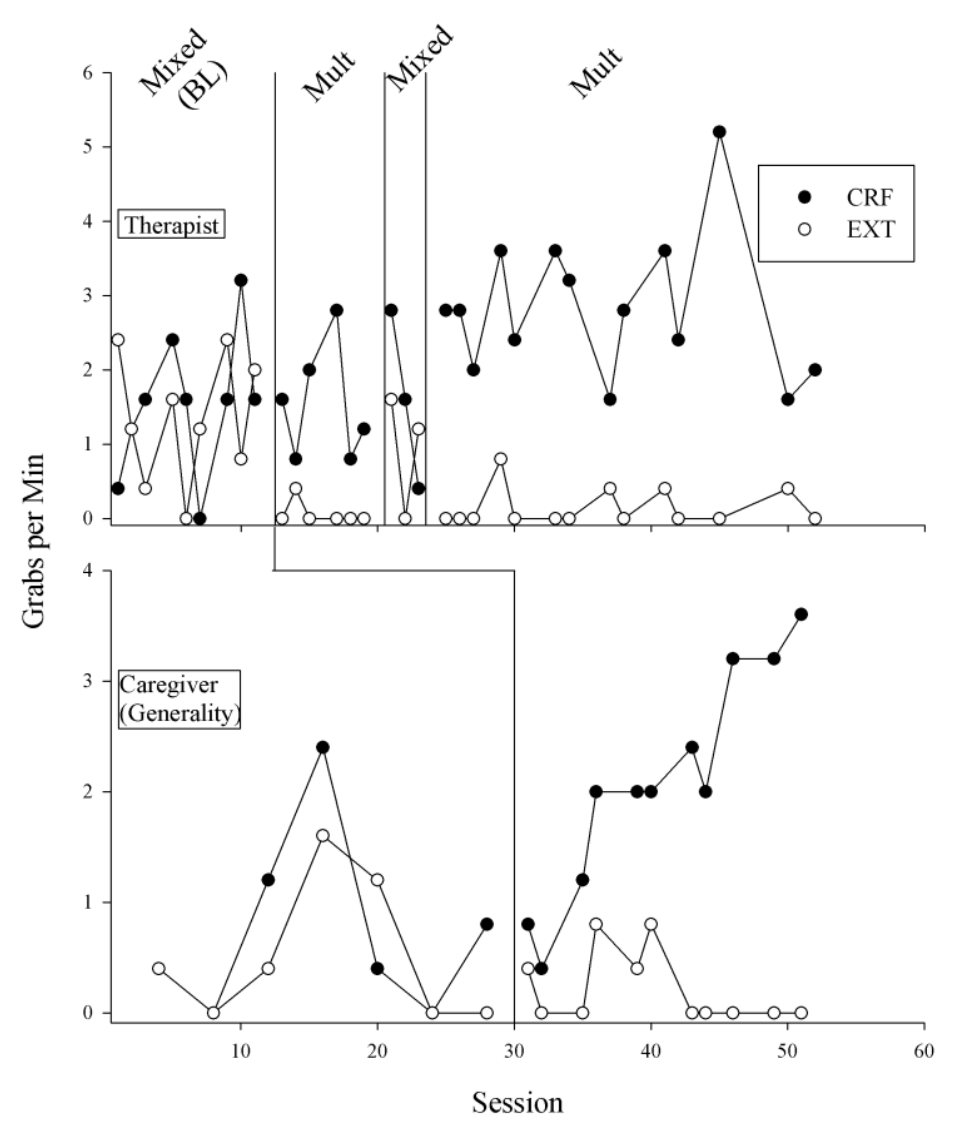

Figure 3. Open circles represent social initiations made during extinction components and closed circles represent social initiations made during CRF components. Under mixed schedule conditions Allan did not discriminate between CRF and EXT components but following multiple-schedule-discrimination training (not depicted) and the implementation of a multiple schedule a there was immediate and pronounced separation between the data paths. 


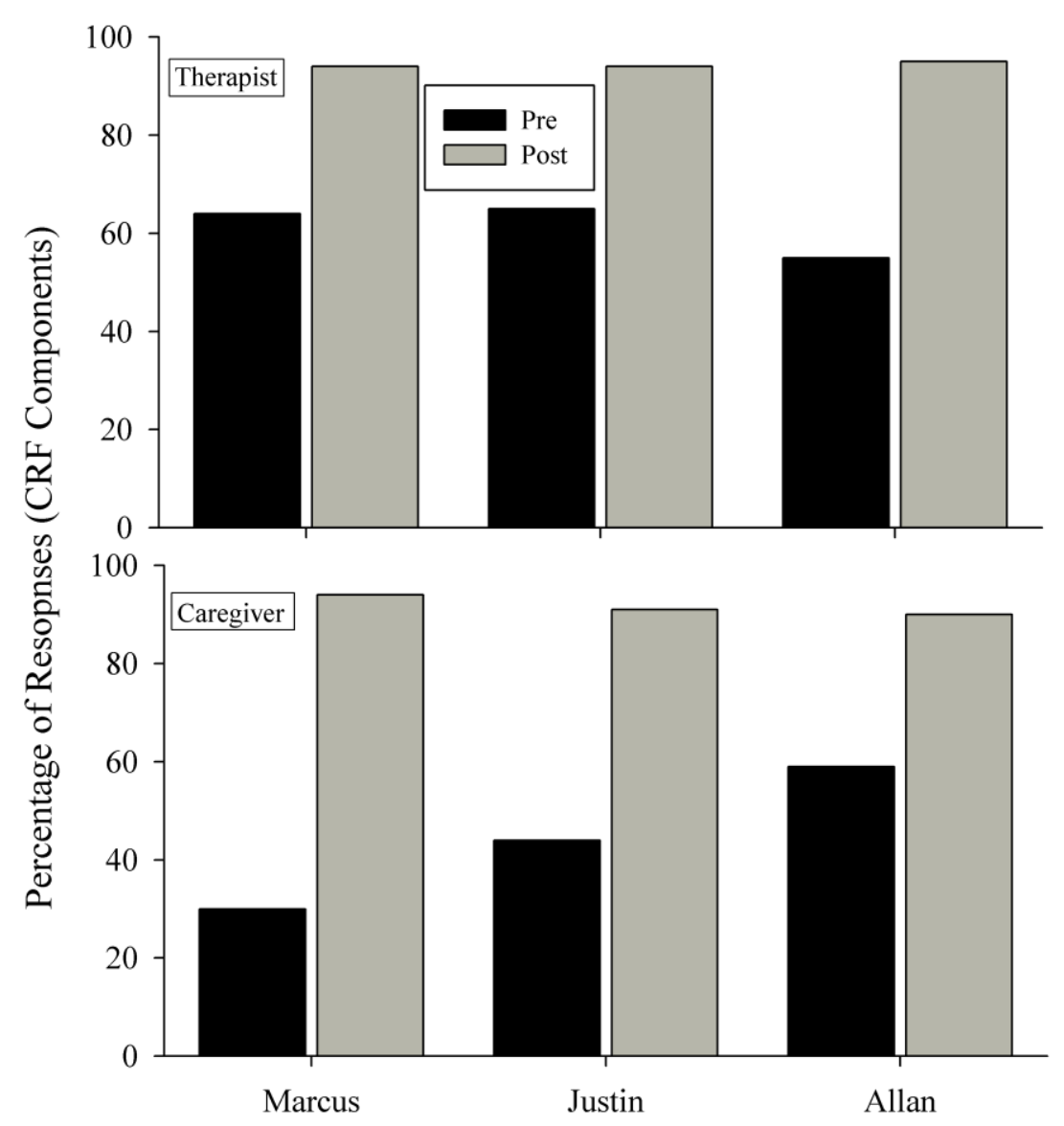

Figure 4. These data represent the percentage of social approaches made by each participant under CRF components during Mixed BL with the therapist (top panel) and caregiver as therapist (bottom panel) and post multiple-schedule-discrimination training. Note that each participant responded at indiscriminate levels during CRF components with the therapist and caregiver before discrimination training. However, following multiple-schedule-discrimination training each participant engaged in near perfect responding during the CRF component with both the therapist and caregiver. 
Table 1

Intervention Rating Profile (IRP-15) Caregiver Responses

\begin{tabular}{|c|c|c|}
\hline & $\begin{array}{l}\text { Justin } \\
\text { Grandmother }\end{array}$ & $\begin{array}{l}\text { Allan } \\
\text { Mother }\end{array}$ \\
\hline $\begin{array}{l}\text { 1. This would be an acceptable intervention for a child's } \\
\text { problem behavior. }\end{array}$ & 5 & 6 \\
\hline $\begin{array}{l}\text { 2. Most parents would find this intervention appropriate } \\
\text { for behavior problems in addition to the one described }\end{array}$ & 6 & 6 \\
\hline $\begin{array}{l}\text { 3. This intervention should prove effective in changing a } \\
\text { child's problem behavior. }\end{array}$ & 5 & 6 \\
\hline 4. I would suggest this intervention to other parents. & 6 & 6 \\
\hline $\begin{array}{l}\text { 5. The child's behavior is severe enough to warrant use of } \\
\text { this intervention. }\end{array}$ & 5 & 5 \\
\hline $\begin{array}{l}\text { 6. Most parents would find this intervention suitable for } \\
\text { behavior problem described. }\end{array}$ & 5 & 6 \\
\hline $\begin{array}{l}\text { 7. I would be willing to use this intervention in a home } \\
\text { setting. }\end{array}$ & 6 & 4 \\
\hline $\begin{array}{l}\text { 8. This intervention would not result in negative side- } \\
\text { effects for the child. }\end{array}$ & 6 & 6 \\
\hline $\begin{array}{l}\text { 9. This intervention would be appropriate for a variety } \\
\text { of children. }\end{array}$ & 5 & 6 \\
\hline $\begin{array}{l}\text { 10. This intervention is consistent with those I have used in } \\
\text { home settings. }\end{array}$ & 4 & 5 \\
\hline $\begin{array}{l}\text { 11. The intervention was a fair way to handle the child's } \\
\text { problem behavior. }\end{array}$ & 5 & 4 \\
\hline $\begin{array}{l}\text { 12. This intervention is reasonable for the problem behavior } \\
\text { described. }\end{array}$ & 5 & 6 \\
\hline 13. I liked the procedures used in this intervention. & 5 & 6 \\
\hline $\begin{array}{l}\text { 14. This intervention is a good way to handle this child's } \\
\text { behavior. }\end{array}$ & 5 & 6 \\
\hline $\begin{array}{l}\text { 15. Overall, this intervention would be beneficial for a } \\
\text { child. }\end{array}$ & 6 & 6 \\
\hline
\end{tabular}

Note. Parents were asked to circle the number which best describes their agreement or disagreement with each statement on a scale from 1 (strongly disagree) to 6 (strongly agree). 


\section{APPENDIX A: Recruitment Letter}

\section{Dear Colleague:}

I am writing to recruit your assistance in identifying potential candidates for a research study. We are evaluating a behavioral intervention to teach individuals with Angelman Syndrome to identify appropriate and inappropriate times to recruit social interaction. As you are aware, one common social problem exhibited by individuals with Angelman syndrome is an intense desire for social interaction, which commonly involves approaching and/or hugging others.

Our research plan is to pair explicit environmental signals (e.g., colored cards, bracelets, or necklaces) with periods in which a trained therapist will and will not reciprocate bids for a social interaction to help teach a discrimination between those two periods. We are hopeful that with continued training, we can then present those signals in the natural environment to control these undesirable social bids.

We are currently seeking five participants who are:

a.) Between the ages of 12 and 17

b.) Diagnosed with Angelman syndrome

c.) Can independently walk or push themselves in a wheelchair

d.) For whom inappropriate social interactions of this sort are a problem.

If you are aware of any individuals who meet these criteria, I would appreciate if you would provide them with my contact information below. I thank you for your consideration and assistance.

Sincerely,

Jeffrey H. Tiger, Ph.D., BCBA-D

Licensed Behavior Analyst

Assistant Professor, Psychology

University of Wisconsin-Milwaukee

2441 E. Hartford Ave.

Milwaukee, WI 53201

tiger@uwm.edu

414-229-4176 


\section{CURRICULUM VITAE}

Caitlin Shea Fichtner (Peplinski)

Place of birth: Milwaukee, WI

Education

B.A., Bradley University, December 2007

Major: Psychology

M.S., University of Wisconsin-Milwaukee, May 2012

Major: Experimental Psychology

Dissertation Title: Teaching Discriminated Social Approaches to Individuals with

Angelman Syndrome

Professional Affiliations

2011- Present Association for Applied Behavior Analysis

2012- Present Wisconsin Association for Applied Behavior Analysis

2012-2014 Mid-American Association for Behavior Analysis

2013- Present Association of Professional Behavior Analysts

Honors and Awards

Dr. Ian \& Lyn Sturrock Memorial Scholarship

Presidential Scholarship

Bradley Special Enhancement Grant

Department of Psychology Outstanding Graduate-Bradley University

Chancellor's Award

John and Lynn Schiek Grant 2010, 2011

Corinne Russell Donley Fellowship 2011, 2012, 2013

Distinguished Dissertator Fellowship 2013

Best Poster Award Wisconsin Association for Applied Behavior Analysis 2013

Teaching Positions

Tutor, Bradley University, 2005-2007

Graduate Assistant, University of Wisconsin-Oshkosh, 9/2008-8/2009

Teaching Assistant, University of Wisconsin-Milwaukee, 9/2009-5/2013

Courses: Introduction to Psychology, Developmental Psychology, Applied Behavior Analysis 
Duties: Lead discussion sections, proctor and grade exams, lead laboratory sections, grade term papers and exams

\section{Clinical Positions}

Behavioral Coach, Wellspring Camps, 6/2010-5/2011

Behavior Therapist, Tiger Center for Applied Behavior Analysis, 9/2011-6/2014

Behavior Analyst, ABA of Wisconsin, 9/2013-Present

Research Positions

Undergraduate Research Assistant

International Sexuality Description Project, 2005-2007

Responsibilities: Coded and entered data

Supervisor: David Schmitt, Ph.D.

Cross-cultural differences in the association between religiosity and HIV status, 2005-2007

Responsibilities: Reviewed literature, designed investigation, developed hypotheses, conducted statistical analyses with SPSS, prepared abstract and poster

Supervisor: David Schmitt, Ph.D.

Detection of deception: Physiological and neurological indices, 2007

Responsibilities: Reviewed literature, designed investigation

Supervisor: Dawn Roberts, Ph.D.

Physiological Correlates of Different Levels of Arousal: EEG and GSR study, 2008-2009

Responsibilities: Reviewed literature, designed experiment, developed hypotheses, conducted analyses with biopac physiograph software as well as SPSS, prepared abstract, paper and poster.

Supervisor: Dr. James Koch, Ph.D.

Examination of Relationships Between Aerobic Exercise and Learning in Young Adults, 2009-2012

Responsibilities: Reviewed literature, designed experiment, developed hypotheses, proposed thesis experiment to committee, conducted analyses, prepared an abstract and paper.

Supervisor: Dr. Rodney Swain, Ph.D.

Teaching Discriminated Social Approaches to a Teen-ager with Angelman Syndrome to Reduce Inappropriate Bids for Attention, 2012

Responsibilities: Reviewed literature, designed experiment, implemented intervention, conducted analyses, prepared an abstract and poster, prepared conference symposium talk, colloquium talk. 
Supervisor: Dr. Jeffrey H. Tiger, Ph.D.

Intermittent Response Interruption in the Treatment of Hair Pulling and Teeth Grinding Exhibited by a Child with Autism, 2012

Responsibilities: Reviewed literature, designed experiment, implemented intervention, conducted analyses, prepared and abstract and poster, prepared manuscript for publication.

Supervisor: Dr. Jeffrey H. Tiger, Ph.D.

Publications

Schmitt, D.P., Youn, G., Bond, B., Brooks, S., Frye, H., Johnson, S., Klesman, J., Peplinski, C., Sampias, J., Sherrill, M., \& Stoka, C. When will I feel love? The effects of personality, culture, and gender on the psychological tendency to love. Journal of Research in Personality. 43(5), 830-846.

Swain, R. A., Berggren, K. L., Kerr, A. L., Patel, A., Peplinski, C. S., \& Sikorski, A. M. (2012). On aerobic exercise and behavioral and neural plasticity. Brain Science, 2(4), 709-744. doi: 10.3390/brainsci2040709

Tiger, J. H., Putnam, B. C., \& Peplinski, C. S. (in press). Developmental disabilities. In F. K. McSweeney and E. S. Murphy (Eds). Handbook of Operant and Classical Conditioning. Hoboken, NJ: Wiley-Blackwell.

McCance, J.E., Tiger, J.H., \& Peplinski, C.S. Treating automatically maintained problem behavior with non-contingent and response-dependent matched stimulation. (in preparation)

Peplinski, C.S., Tiger, J.H., Teaching Discriminated Social Approaches to Individuals with Angelman Syndrome. (under review)

Presentations

Schmitt, D.S., Peplinski, C.S., \& Sampias, J. (2007, November). Religion and the links between HIV knowledge and HIV risk across cultures, genders, and generations. Poster presented at the meeting of the International Association for Relationship Research, Melbourne, NSW, Australia.

Peplinski, C.S., Koepke, J., \& Koch, J. (2009). Physiological Correlates of Different Levels of Arousal: a study with Electroencephalogram (EEG) and Galvanic Skin Response (GSR). Poster presented at Neuroscience 2009, Chicago, IL.

Peplinski, C.S. \& Tiger, J.H. (2012, October). Teaching discriminated social approaches to a teen-ager with Angelman syndrome to reduce inappropriate bids for 
attention. Poster presented at Mid-American Association of Behavior Analysis 2012, Minneapolis, MN.

Peplinski, C.S. \& Tiger, J.H. (2013, May). Teaching discriminated social approaches to a teen-ager with Angelman syndrome. Symposium talk presented at Applied Behavior Analysis International 2013, Minneapolis, MN.

Peplinski, C.S. \& Tiger, J.H. (2013, May). Intermittent response interruption in the treatment of hair pulling and bruxism exhibited by a child with autism. Poster presented at Applied Behavior Analysis International, 2013, Minneapolis, MN.

Peplinski, C.S. \& Tiger, J.H. (2013, August). Intermittent response interruption in the treatment of hair pulling and bruxism exhibited by a child with autism. Poster presented at Wisconsin Association for Applied Behavior Analysis, 2013, Madison, WI.

Peplinski, C.S. \& Tiger, J.H. (2013, August). Teaching discriminated social approaches to a teen-ager with Angelman syndrome to reduce inappropriate bids for attention. Poster presented at Wisconsin Association for Applied Behavior Analysis 2013, Madison, WI.

McCance, J.E., Tiger, J.H., \& Peplinski C.S. (2013, October). Treating automatically maintained problem behavior with non-contingent and response-dependent matched stimulation. Poster presented at Mid-American Association for Behavior Analysis, 2013, Pewaukee, WI.

McCance, J.E., Tiger, J.H., \& Peplinski C.S. (2014, March). Treating automatically maintained problem behavior with non-contingent and response-dependent matched stimulation. Poster presented at Association for Professional Behavior Analysts, 2014, New Orleans, LA. 